\title{
POTENTIAL OF PUBLIC OPEN SPACES TO MOTIVATE THEIR USERS TO ENGAGE IN PRO-SUSTAINABLE ACTION
}

\author{
UDO DIETRICH \\ REAP research group, HafenCity University Hamburg, Germany
}

\begin{abstract}
People and their habits, perceptions and actions, are critical to reaching sustainable development goals. This paper investigates the role of public urban spaces in motivating their users to pro-sustainable action. Psychological literature is used to select methods of how to motivate people. It describes the triggers for our activities. Of first priority is the target that activities should not have detrimental consequences for us personally or for our family and close friends. Of secondary priority are activities that might lead to an improvement in quality of life, but here the decision is not always clear and we often hesitate to act. We are also guided by orienting our activities according to common rules, norms and standards. To be regarded as a good citizen can be a strong motive. The adaptation of these motives to sustainability shows several potentialities while also avoiding detrimental consequences. Here the circle of those involved is much larger - it comprises the entirety of mankind and also future generations. Because we do not see the immediate advantage to us and our inner circle, we may hesitate to take important actions. These methods are applied to the special case of public open spaces where the fact that they are a common good can be used to advantage. The basic principle is to utilize and develop positive emotions tied to sustainable urban interventions and to avoid reactance effects. Detailed recommendations for interventions (fostered by an administrative body) are derived. Furthermore, the paper provides policy guidelines to increase involvement of citizens through tailor-made strategies by the activation of cooperative mechanisms in public urban spaces. Selected examples of two cities, Hamburg and Nice, were collected and analyzed according to these recommendations.

Keywords: public open spaces, pro-sustainable action, motivation, SDG, common good, mechanisms of cooperation, policy guidelines.
\end{abstract}

\section{INTRODUCTION}

It is common in scientific literature to write in an impersonal style by using the passive voice. This article is purposefully written in an active voice and uses the collective "we" form that expresses that we are all directly concerned by climate change and humanity must act and adapt together. Nobody is so small that they cannot participate in sustainable development, and we all must reflect on our daily behavior and activities.

For the description of human behavior, decisions and activities a wide range of models are known in psychological literature [1]-[6]. Within the relevant literature, specific and partly different terms are sometimes used for identical statements. For the adaptation to public open spaces the relevant contents were selected, further developed and brought into a description that is free of contradictions. For that reason, literature is furthermore only cited again if there is a direct relation to the content.

\subsection{Basic mode of personal activities}

In general, we act in a way that does not deteriorate the present situation of our personal life, or still better, improves it. Because these actions are related to our own personal life, this includes the persons nearest to us: family and close friends. 
Of first priority are decisions that avoid detrimental consequences. That force is very strong and decisive. After risk perception and assessment [1] activity follows immediately if we see any risk of a decrease in our quality of life.

Of second priority are decisions that will likely improve quality of life. Often we hesitate because it is not certain whether it will really improve or if there could be negative by-effects. We know what we have now, but we do not know what we will have tomorrow.

\subsection{Personal activities in the milieu of a society}

Each human is part of the surrounding society. That society shapes a set of norms that organize daily life, with some partly fixed by laws and regulations (wearing a seatbelt in a car), others are more diffuse and societally defined ("people don't do that"). This set of norms is a result of the collective experience of the society. It might be considered too abstract to deliver concrete advice for personal decisions, but it will be used as a framework. The more diffuse the norm, the more variation exists in its form and potential for contradictions - with the "right" ones then selected by personal decision. The basic principle here is the wish to be a good member of society and to not appear negatively.

That set of norms is selected, adapted and transferred to the personal set of norms that forms the main guideline for personal decisions. Personal norms strongly influence one's behavior in concrete situations (communicate or not with unknown persons if they are nearby, in public etc.). These personal norms are mostly generated from personal experiences. A negative experience will lead to the norm to avoid an equivalent activity; a positive one invites one to repeat the equivalent activity.

General ethical principles (like respect, empathy but also sustainability etc.) are used to shape the set of norms for the society as well as a guideline for personal ones.

We perceive it as optimal if that set of norms would not have to be changed if it is once gained. Each change would be accompanied with the feeling of uncertainty and would have to be confirmed by the next decisions in our daily life. Nevertheless, we adapt and optimize our set of norms throughout our lives based on negative and positive experiences as well as changes in the surrounding society. But, our tendency is to try to keep the change rate as low as possible and in general we react more out of compulsion. A change in our normative behavior is commonly related to a negative feeling and not to a positive learning process - we perceive it as a defeat if the previous set is no longer working optimally and we are forced to adapt it.

\subsection{Triggers and barriers}

A planned activity can be transformed into a real one by different triggers but can also be hindered by barriers.

\subsubsection{Triggers}

Main triggers for activities can be the anticipation of a positive feeling/the avoidance of negative feeling [2]:

- Curiosity

- Novelty (new experiences)

- Activity is easy to execute

- Community feeling and social proof (doing the same as the others)

- Expected confirmation of own assessment

- Scarcity (happy hour in a bar) 
- Reaction to a (stimulant) provocation

- Proof of own capabilities

\subsubsection{Barriers}

Barriers can be external and objective (no bike lane), or internal in the social range (majority behaves different), and the psychological/personal range (habits, lack of courage, missing know-how). If rational (social) and emotional (psychological/personal) arguments contradict, we often decide emotionally (I agree that public transportation is good for the environment but I do not feel safe in it) [3].

Missing direct perception also hinders corresponding activities [2]:

- Events are too far away, geographically or in the future.

- Processes act very slow (increase of sea level) and at a small scale.

- Missing understanding of exponential processes and tipping points.

- Problems are too abstract, diffuse and complex.

\subsection{Personal activities and sustainability}

\subsubsection{Sustainability}

Sustainability is the endeavor to maintain our planet in a way that future generations will have the same (or better) preconditions to live as we have in present times. The different aspects are described by the 17 sustainable development goals (SDG) of the UN (Fig. 1).
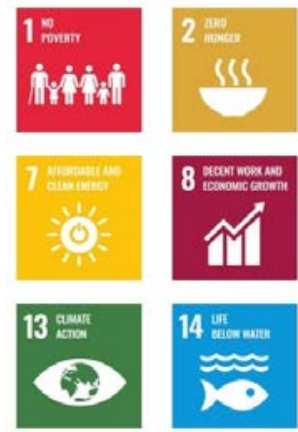
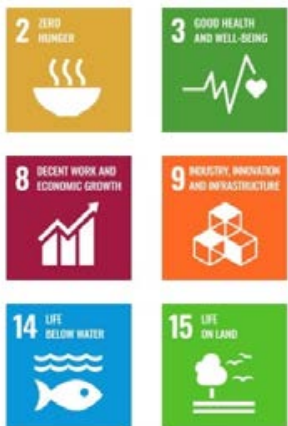
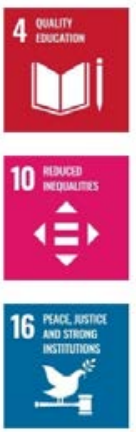
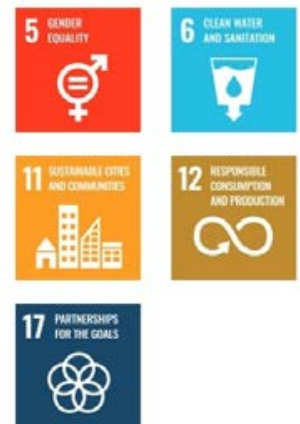

Figure 1: The 17 sustainable development goals (SDG) of the United Nations [7].

Goal no. 1 and 2 are basic preconditions but many of the other goals are directly related to cities and their administrations. Besides the central goal of no. 11, these are no. 3 to 5 and 10 for personal social welfare, no. 8, 9, 10, 13, 16 and 17 for welfare in the society, and no. 6, 7 and 12 for energy, material and water.

Current knowledge confirms that the technological answer to these SDG's will not be sufficient [8]. An increase in efficiency as a single measure will not lead to success. It is necessary to involve people in the process, for they have to accept the changes. Optimally they should become active members of the society, true citizens. Civic participation in local and central decisions would guarantee a perspective that is more farsighted than those of politicians that only have the next elections in view. A change in the way of living is a central component to the necessary transition. The principle of sufficiency (without a reduction in happiness!) plays a decisive role here, too. 
For personal activities, the analysis and choice of the most sustainable decision from a bundle of different possible decisions is very complex. Often an exact assessment is not possible because there are too many uncertainties in a society's future development. Often an activity has a sustainable character but includes unsustainable components as well (e.g. burning waste to heat our buildings is positive because it replaces other fossil fuels, but the generation of waste in general is negative). Or, for example, decide what is better: to buy an apple that is produced organically but far away or an apple that is produced locally and fairly but is not organic?

Sustainability is regarded very differently by different parts of society and has many different perspectives, including personal, social, present and future viewpoints.

\subsubsection{Personal motivation}

As described in Section 1.1 our personal activities are concentrated on concrete persons and things that ensure the welfare of one's own family and close friends, today and in the (near) future.

All other groups that contribute to personal activities are of lower priority, such as future (unborn) family members, humans outside our personal surroundings, and future generations. The character of these groups is more abstract, impersonal, diffuse, invisible and uncertain. Poor people, minorities that are hardly perceived in their own society, far away foreign societies (e.g. fair trade - is welcome in the mind but does not necessarily lead to concrete activities - I do not see the farmer far from here), future societies we cannot precisely imagine - all can be easily pushed aside in our minds.

What we do not see directly is often not included in our decisions. As an illustrating example we give the story of fair-trade bananas in a German supermarket chain [9] - the supermarket offered them as a step toward sustainability, respect and fairness (Fig. 2). The price was $10-20 \%$ higher than for the conventional bananas - which were still offered by a competitor. As a result the customers went to buy the cheaper bananas not asking for sustainability. Thus, the initiative was taken back and now both sorts of bananas are offered at the supermarket chain.

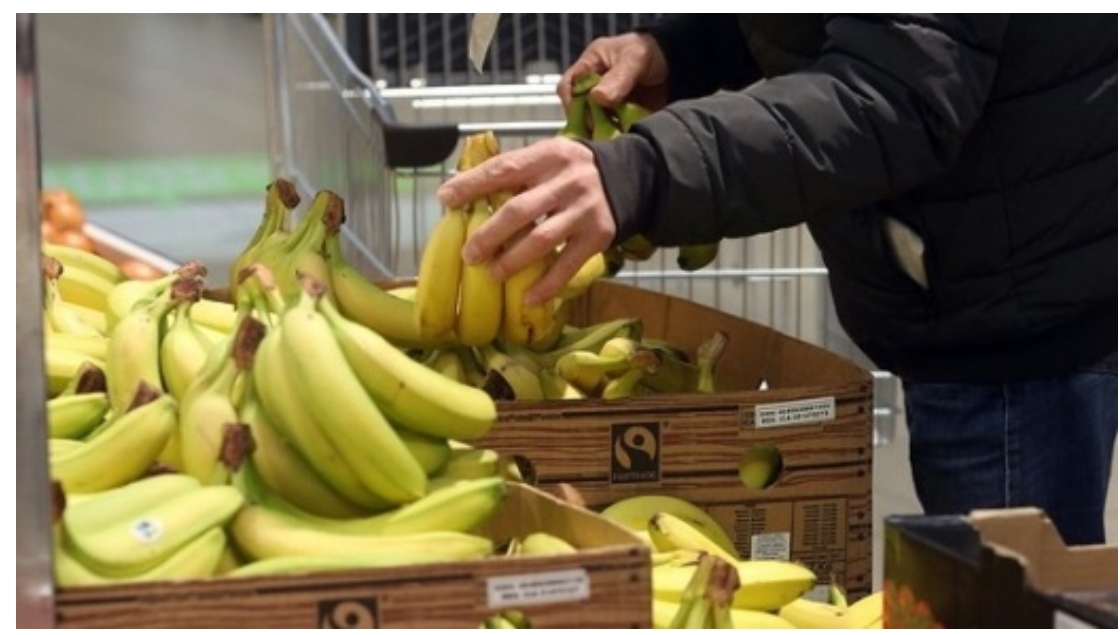

Figure 2: Fair trade bananas. To change the offer completely to fair trade was not a commercial success. Another competitor sold standard bananas a few cents less. As a result, the supermarket now has both sorts on offer [9]. 
In Germany, renewable electricity suppliers have a market share of only $9 \%$ [10]. It is hardly chosen even if the price difference is only about $15 \%$ higher, which ends up being 10 to 15 Euros more per month for an average household - the price of two cinema tickets.

\subsubsection{Motivation stimulated by own society}

Outside of the sphere of the nearest persons we live in is a society that surrounds us.

At a national/regional/city scale we share and accept social norms and standards (see Section 1.2). The strongest motivation to act is again to avoid negative feelings. We try to behave like the others and to avoid that the others frown at us because we behave outside of the usual norms and standards. We see the other people and can communicate more or less directly which allows us to feel included and secure - making us want to be a good member of that society. We do not litter something in public, dog owner's care for their excrements. We collect and separate waste.

This social proof is the strongest force for motivation [2]. It can be a trigger for activity (a person adapts to the majority) and at the same time a barrier if there is a need to change the norms and standards of the whole society at once (one is waiting until the other takes the first step).

At the global scale there are many different systems of norms and standards in different regions. They can sometimes be partly in contradiction (beef and pork as accepted food) and thus do not deliver immediate guidance to act. Furthermore, people are far away and invisible, the social proof cannot be used as a measure for orientation. On the contrary, if we stay at a location where regional standards and norms are different, we tend to not accept them and behave furthermore as we would in the system we are accustomed to ones (e.g. wearing shorts or laying topless on the beach) thus defending it a bit like it is the right or better norm.

The only framework we have are general ethical principles as well as an understanding of complex processes in (future) development. These principles are generally accepted but do not lead to activities at the personal scale [4].

But, if problems and events at global scale can be processed in a way that they become visible and comprehensible to us and we perceive it as happening in our regional/personal surrounding, the well-known mechanisms start to work. In the case of a concrete event (flood, earthquake) where human sorrow is visible even if far away, we donate high amounts of money. If we see the working conditions in a factory that produces clothing for developed countries we ask next time for a fair trade T-shirt etc.

That transfer from the global to the regional scale can be a strong trigger to include global environmental problems in our activities. Finally it would contribute to a corresponding adaptation of the regional norms and standards.

\section{MOTIVATION TO ACTIVITIES THAT SUPPORT SUSTAINABILITY}

\subsection{Problem of human behavior and needs of sustainability}

Human behavior is not well suited to make the right decisions in regard to sustainability. That would mean to set the welfare of future generations above that of one's own generation. The priorities are set in opposition and in addition the field of sustainability is complex and uncertain.

Finally, we know well in our mind that when we do something unsustainable, we can experience feelings of guilt. Our way of living is at the expense of other parts of our own society, other societies/countries, future societies, environment, nature, fauna and flora 
etc. - but we do not always make the necessary changes in our activities. To pass that threshold, a wider change in social norms seems to be necessary.

Such a social transition process seems to be picking up pace. That gives the hope that in the very near future, social tipping points (e.g. the recent and rapid change to smoke-free public areas in buildings) will occur and change our way of living in a very short period of transition. In the Social Tipping Dynamics [11] six fields of social tipping elements were identified:

- Energy transition

- Human settlements (buildings and energy use)

- Financial markets (divestment from fossils)

- System of norms and values

- Education

- Information feedback

There is already one group in today's society that could trigger this development. Parts of the younger generation are actively participating in accordance with aspects of sustainability. They act out of a fear that their own lives will be less prosperous (economically, socially and environmentally) than their parents. The Fridays for Future movement shows the power that it can reach. But what will happen to those same activists when they have their own children - will they continue to act or will they become as unprogressive as their parents?

Very positively, there is a clear difference in behavior between the young generation and that of their parents. Vegetarian and vegan diets, use of public transportation, conscious abandonment of unnecessary consumption, can all be noted.

In theory, our society has the power to realize nearly every target in regard to sustainability - simply by our behavior in consumption. If nobody would buy vegetables from far away, meat coming from industrial agriculture, unethically produced clothing or electricity etc. - industries would have to immediately follow suit. In that sense, every single person is really responsible for the future development. In spite of the fact that the majority would have enough money to make these changes, the short term advantages dominate the long term negative impacts.

This typical human behavior has to be regarded if interventions that lead to sustainable activities should be successful.

\subsection{The potential and role of cities}

Cities form a frame at the regional scale that gives supplementary identity. They should use that position to motivate their inhabitants to pro-sustainable behavior. The corresponding method would be to contribute toward making it a social norm. Through their interventions, cities have an excellent potential to deliver their inhabitants a feeling of being part of a local society, of being true citizens.

Consequently, interventions should concentrate on the city scale itself, to give their inhabitants the feeling of security (I pay taxes but what I receive back from the city has a much higher value) and to strengthen positive emotions of being a citizen. Cities should invite and involve their inhabitants to participate in the city's development, by bottom-up measures and also by extended participation in political decisions and processes (civic participation, assembly of experts etc.). By doing that, cities can actively contribute to extend the basis of decision making from the thinking at the "me" scale to the "we" scale. 
Supplementary, cities can contribute to make global problems visible and comprehensible (e.g. international network of cities) to participate in the transfer of global problems to a regional scale that would be a step to creating true world citizens.

\subsection{Recommendations for the design of motivating interventions}

How do we reach the inhabitants of a city and motivate them toward a more sustainable behavior? The first, step is already done - the feeling of doing something wrong, but the feeling is still negative and does not lead to concrete changes. Now it has to be further developed and turned into a positive behavior - that is the main action principle of interventions in public spaces.

\subsubsection{Avoid reactance effects}

Any intervention can cause undesired negative as well as desired positive effects.

A first basic design principle is to avoid reactance [5]. If people feel overstressed and do not see how a positive activity could easily be realized then they go into defense and find arguments to not change their behavior. Such an effect would be counterproductive because it still reinforces the negative side. Typical strategies of reactance are:

- Denial of problems with sustainability

- Distortion of reality (fakes)

- Transfer of responsibility to others (I am too small)

\subsubsection{Use and develop positive emotions}

Interventions should use the burgeoning feeling of responsibility and foster the ability to develop it further to motivate toward detailed sustainable activities [2], [4].

As a first step, the delivered information should be detailed, precise, sincere, objective, correct and current (scientific, statistical etc.). This allows people to analyze the situation and to be conscious about it.

Proposals for detailed personal activities that are easily realizable in a short time would help to find out one's best personal decision in a concrete situation. The method of how to come to such ideas is also transferred along the way.

Give feedback that is detailed and (ideally) quantitative so that people can assess their impact successfully. This also allows one to compare the effectiveness of different measures and to select the best one.

Foster the self-efficacy of people; make them active members of the society. Invite community members to participate, foster a collaborative space where members get to know one another and work together.

Invite people to contribute to political decisions on local scale. Foster social recognition of people that are active in sustainability. Prominent persons can act as good examples.

To break habits for a short time through incentives (e.g. one week cost free public transportation) could be a helpful starting point for changes in personal norms. In the same way interventions could have persons as a target group that are in a change between two phases of their lives: beginning of the studies, marriage, moving to another apartment, a child, beginning of retirement etc.

Interventions should show a vision and contribute to bringing new standards and norms into practice. A reward (financial as well as social) may help to activate people. But in the center of the information should be the main intervention (cargo bicycle, see section 3 ) and the reward should be mentioned only secondarily. A reward at the center would cause the effect that people only seek the reward and continue with their old habits. 
2.3.3 Special recommendations for interventions in public spaces

Obviously, the time when people are confronted with the information is quite short if persons are in transit through that space. Only if they choose to stay there would the time be longer. Thus interventions should be tailored so that they can act in a short time. Supplementary to the rules above the following criteria are recommended [2], [4]:

- Activate the viewers emotional side but do not cause fear.

- Create networks to spread information - public spaces can help here as a multiplier.

- A clear, simple message, easy to understand, read, see - even in a few seconds.

- Pack it in a story, message, movie etc.

- Address the persons directly, through a direct personal message using concrete (prominent) persons that are substitutional to themselves.

- Personalize abstract environmental information ("your children...", "the food you eat...”).

- Relate to local institutions, locations, specialties.

- Present city's bottom-up initiatives.

- Inform about initiatives of the administration/government, presented as an offer to the people.

- Show concrete possibilities to act, related to city scale, best in little, simple steps.

- Use a commitment as a frame that links inhabitants to the city, make personal engagement visible (donate to plant a tree; a badge with your name will be mounted on it etc.).

- If quantities are mentioned use units that relate to one person ( $1 /$ person, $\mathrm{kWh} /$ person, $\mathrm{CO}_{2}$ per person etc.).

- Combine with other events (weekly markets etc.).

\subsubsection{Beneficial use of public open spaces as a common good}

Public open spaces are a common good that has to be shared between all users. The question of how that space should be used by the community in the fairest way is closely related to sustainability. To whom belongs the (limited) space between the building's edges in a street? Car lanes, bike lanes, sidewalks, terraces, benches, pocket parks - which distribution corresponds to the "right" use?

Interventions can make people aware that we live in a community and are responsible for the entirety of humanity. Then the step from "me" to "we" will be supported.

\subsection{Present strategies of German government and administrations}

The German central government and the local administrations follow the principle that they do a lot of things toward sustainability, but they do not always inform the public directly. The reason seems to be the fear that the population will not follow these changes and that they will lose even more votes to the ultra-right party in the next election [12].

In the city of Hamburg, extensive road construction work is in progress resulting in more bike lanes and fewer car lanes, all without any detailed announcement. Additionally, a new subway line is planned but the corresponding information and advertisement is present only inside the subway system and not at street level. Hamburg is also replacing all combustion buses with electric buses. These new e-buses look like any other (combustion) bus and there is no special design or information (or it is hardly visible) that demonstrates this new sustainable transportation practice. 
All these measures are positive and a step toward a sustainable city. But the secrecy that surrounds their realization is an unused potential to motivate the inhabitants further.

\subsection{Necessary strategies of government and local administrations}

By acting covertly, the administration does not use the high potential of involving the inhabitants. This is not sufficient; people must be informed and brought on board. We need a population that is active and part of the development. We need (more) basic-democratic structures like referendums on basic questions and decisions. Politicians think only in shortterm periods until the next elections. People (especially parents) must think in long-term that is what we need! An activation of people, an active participation also contributes toward the awareness of problems, open discussion and changes in the set of social and personal norms.

\section{EXAMPLES}

\subsection{Electrical buses}

Many cities have transitioned from combustion motors to electrical motors. Fig. 3 shows examples from Hamburg (Germany) and Nice (France). In Hamburg most of the e-buses look like any other bus and are mostly indistinguishable. Only a few carry the information outside, even here the abstract term "emission free" is used - in (too) small letters. In Nice, standard buses are orange (like in Hamburg) but the e-buses are in vibrant red and the message is clearly visible in huge letters: zero pollution, zero noise, $100 \%$ electric [13].

To be perfect, a smile could be added, a direct invitation ("come in, enter the bus and check the new feeling out") and general information about the process ("for the welfare of their guests and inhabitants, the city of Nice will replace all the buses by 2025 ").
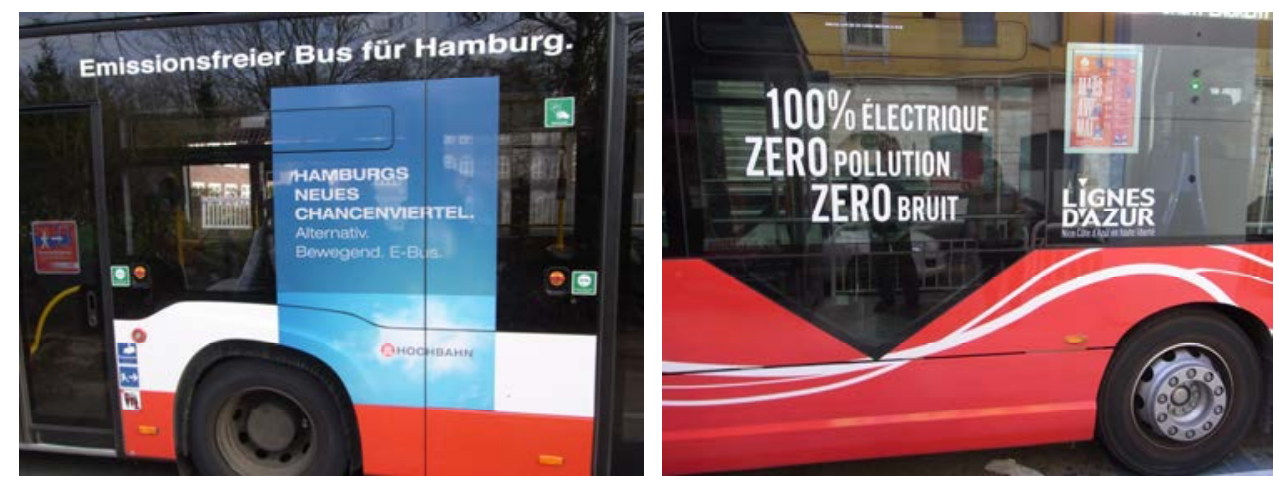

Figure 3: E-buses in Hamburg (left) and in Nice (right). (Source: Author.)

\subsection{Cargo bicycles}

The city of Hamburg gives financial support for the private acquisition of cargo bicycles, if a combustion car is taken off the road for it; the amount paid is still higher (Fig. 4, [14]). The initiative has been unexpectedly successful and will have a second round, in total more than 2 million Euros are invested. 

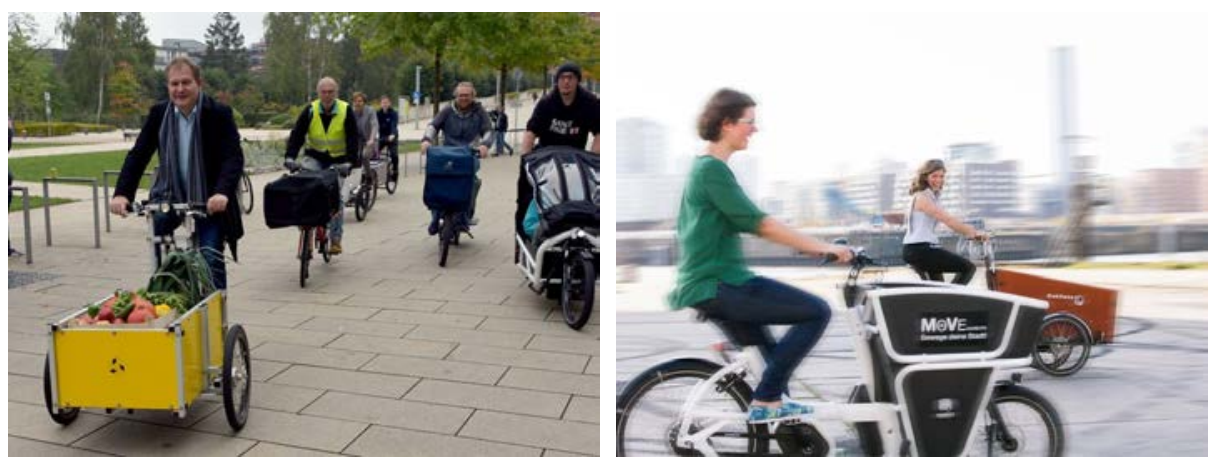

Figure 4: Selection of cargo bikes for Hamburg. The city gives financial support for the acquisition, especially if the business will cease to use a car [14].

The idea that shop and restaurant owners but also private persons use a cargo bike instead of a car is excellent. What would make it perfect would be to create a brand (like a "Hamburg cargo bike") that is visualized with badges on the bicycles and an advertisement for the initiative in the public.

\subsection{Streets for pedestrians and cyclists}

The initiative "Ottensen macht Platz" (the quarter of Ottensen gives space) started from an NGO (Cities4people [15]) but was then taken and reinforced by local authorities [16]. In the quarter several streets were closed for cars (with exceptions for inhabitants, emergencies, craftsmen etc.) and temporarily pedestrianized and equipped with corresponding street furniture (Fig. 5). All interventions were paid for by the city of Hamburg. The first phase had an experimental character and was limited to a 6 month trial. Results were analysed by Technical University of Hamburg, and they show that the initiative is widely accepted with the clear majority wishing to turn it into a permanent situation (maybe with minor adaptations for cars). The project was so far a full success, now the final realisation would be the task of the city's administration.
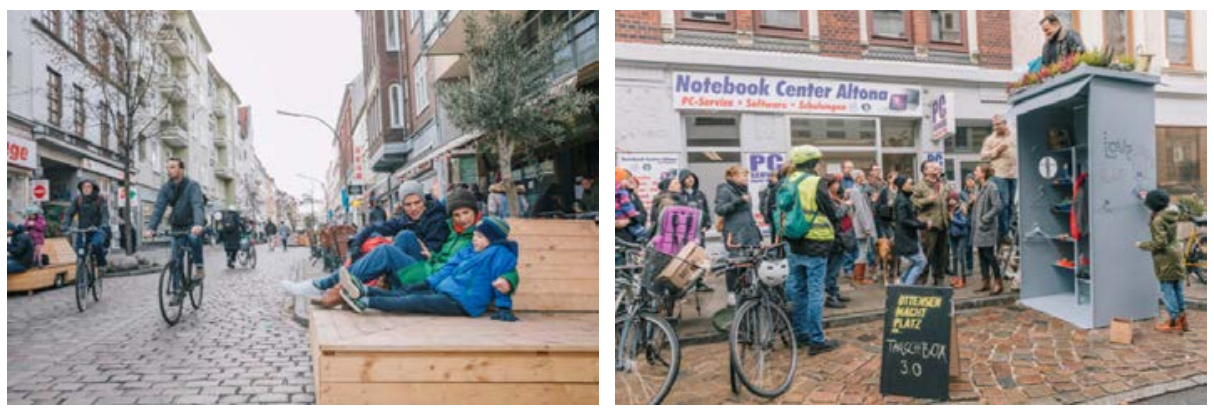

Figure 5: "Ottensen macht Platz" (Ottensen gives space) - initiative in a quarter of Hamburg [16]. Streets were pedestrianized temporarily to gain experiences of whether that initiative is well accepted or not. 

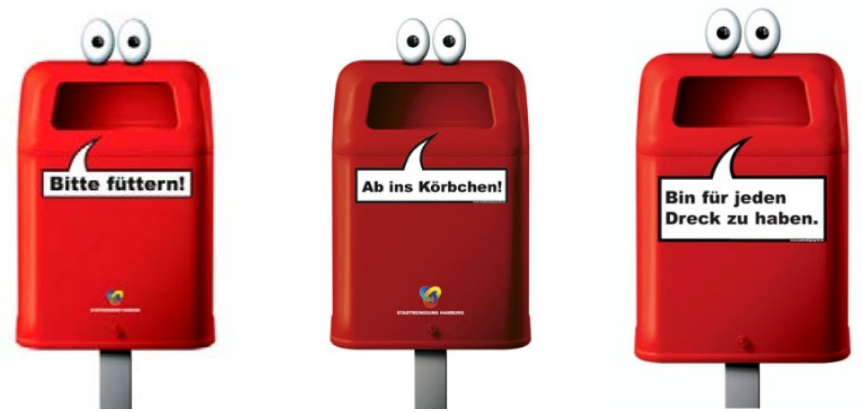

Figure 6: Public waste bins in Hamburg [17]. In total about 50 different designs exist - to explore in the whole city (for translations see text).

\subsection{Public waste bins}

The city of Hamburg installed a specially designed type of public waste bin. They are everywhere, their number is sufficient and the maintenance and collection have been successful. Their distinctiveness is their attractive and inviting character simply by putting on the bins sayings that are reminiscent of small talk (Fig. 6, "please feed", "I feel so empty" etc.). The same enterprise offers a special application to send pictures and locations of littered places to the city administration for quick cleaning [18].

Both initiatives invite inhabitants to active participation. The waste bins work with humour and the visualisation of their message, the application utilises contemporary media - both create a positive feeling with their use as well as a feeling of being part of the city.

\section{FINAL REMARKS/CONCLUSIONS}

The Corona-crisis of 2020 showed that public authorities were well able to use public spaces for information and guidance of the inhabitants. Strong interventions were possible through advertisements (Fig. 7), locked children's playgrounds, controls by policemen etc. These measures were widely accepted.

The difference to pro-environmental behaviour is obviously that the "enemy" here is directly visible and concrete. The environmental crisis is (too) far in the future and much more complex. If we are to create a more sustainable future, it would be necessary to reach the same level of success as the actions made to combat the coronavirus.

\begin{tabular}{|c|c|}
\hline fintuverzicntbar & Stay home, hold together! \\
\hline $\begin{array}{l}\text { Zu Hause bleiben, zusammenhalten! } \\
\text { Hände waschen, } \\
2 \times \text { Happy Birthday singen! }\end{array}$ & Wash hands, sing two times happy birthday! \\
\hline $\begin{array}{l}\text { Keine Bussis und Umarmungen, } \\
\text { dafür öfter lächein! }\end{array}$ & No kisses and embrace, smile more often instead! \\
\hline $\begin{array}{l}\text { Keine Panik, nicht hamstern, } \\
\text { einander helfen! }\end{array}$ & No panic, no stockpiling, help each other! \\
\hline 9 & Your pharmacy - simply indispensable \\
\hline
\end{tabular}

Figure 7: Public advertisement in Hamburg referring to the Corona-events in 2020. (Source: Marina Montelongo, HafenCity University Hamburg.) 


\section{REFERENCES}

[1] Wilson, C. \& Dowlatabadi, H., Models of decision making and residential energy use. Annual Review of Environment and Resources, 2007. www.researchgate.net/publication/228255686_Models_of_Decision_Making_and_ Residential_Energy_Use.

[2] Manning, $\overline{\mathrm{C}}$., The Psychology of sustainable Behavior, Minnesota Pollution Control Agency, 2009. www.pca.state.mn.us/sites/default/files/p-ee1-01.pdf.

[3] Mueller-Eie, D. \& Bjorno, L., Urban sustainability and individual behavior. WIT Transactions of the Built Environment, vol. 1, WIT Press: Southampton and Boston, pp. 29-40, 2015. www.witpress.com/Secure/elibrary/papers/SD15/SD15003FU1.pdf.

[4] James, R., Promoting Sustainable Behaviour. A Guide to Successful Communication. Berkeley University, 2010. www.sustainability.berkeley.edu/sites/default/files/ Promoting_Sustain_Behavior_Primer.pdf.

[5] Hamann, K., Baumann, A. \& Koeschinger, D., Psychology of Environmental Protection. https://wandel-werk.org/Handbuch.html.

[6] Ajzen, I., Behavioral interventions based on the theory of planned behavior, 2019. http://people.umass.edu/aizen/pdf/tpb.intervention.pdf.

[7] UN, 17 Sustainable Development Goals. www.un.org/sustainabledevelopment/news/ communications-material/.

[8] IPCC, Global warming of 1.5 degree, special report for policy makers, 2018. www.ipcc.ch/sr15/.

[9] Fair trade bananas, 2019. www.t-online.de/leben/essen-und-trinken/id_85774380/lidlmuss-bei-fairtrade-bananen-zurueckrudern-was-sind-die-gruende-.html.

[10] Market share of electricity suppliers in Germany, 2020. https://1-stromvergleich.com/ stromanbieter-deutschland-marktanteile/.

[11] Otto, I.M. et al., Social tipping dynamics for stabilizing Earth's climate by 2050. PNAS, 117(5), pp. 2354-2365, 2020.

[12] Fridays for Future demonstration, Freiburg im Breisgau, Speech of Ernst Ulrich von Weizsäcker, 29 Nov. 2019.

[13] $100 \%$ electrical buses in the city of Nice, 4 June 2018. www.nicematin.com/vie-locale/ dici-a-2025-il-ny-aura-plus-que-des-bus-electriques-sur-le-reseau-lignes-dazur235578. Accessed on: 14 Mar. 2020.

[14] Financial support of the city of Hamburg for the private acquisition of cargo bicycles. https://moinzukunft.hamburg/lastenrad-programm. Accessed on: 14 Mar. 2020.

[15] Cities4people, NGO for pedestrian and bike friendly cities. https://cities4people.eu/. Accessed on: 14 Mar. 2020.

[16] Ottensen macht Platz, local initiative in Hamburg. https://ottensenmachtplatz.de/. Accessed on: 14 Mar. 2020.

[17] City of Hamburg, Red public waste boxes. www.stadtreinigung.hamburg/ privatkunden/strassenundwege/papierkoerbe/. Accessed on: 14 Mar. 2020.

[18] City of Hamburg, application to send picture and location of littered places to the city administration for quick cleaning. www.stadtreinigung.hamburg/privatkunden/app/. Accessed on: 14 Mar. 2020. 